\section{Endoscopic ultrasound-assisted endoscopic sub- mucosal dissection of a gastric subepithelial tumor}

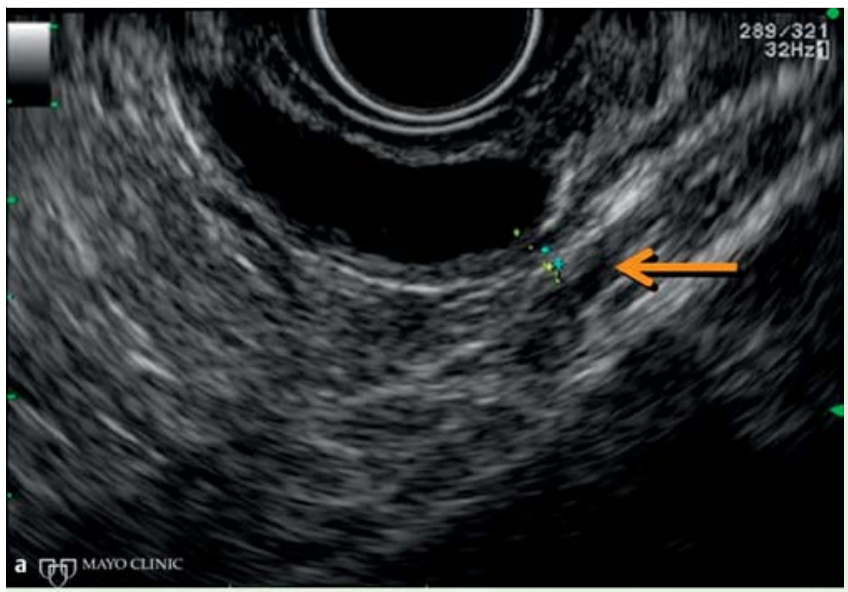

Fig. 1 Curvilinear endoscopic ultrasound of subepithelial lesion in a 56 -year-old woman demonstrating its close proximity to: a the diaphragm (arrow); and b: the splenic artery (orange arrow).

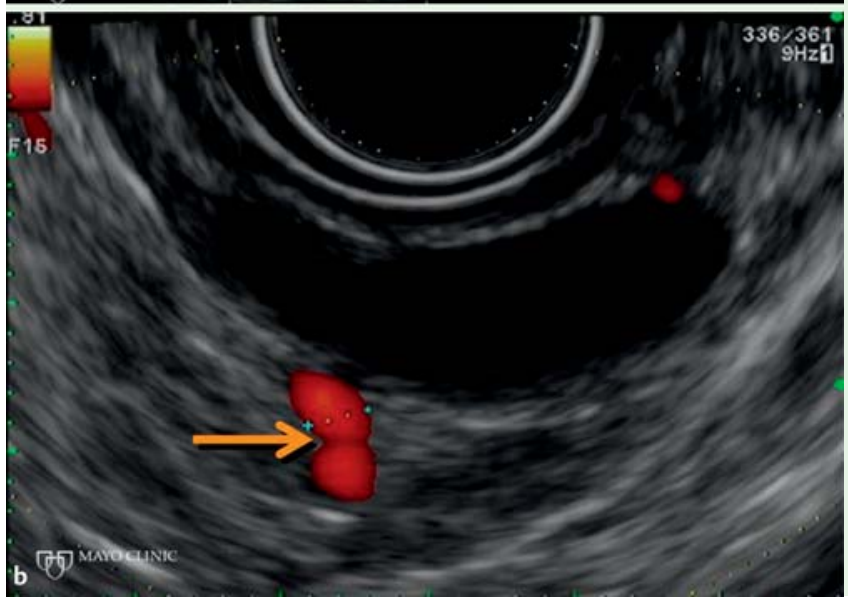

The malignant potential of subepithelial lesions is difficult to establish before resection. Concerns regarding endoscopic submucosal dissection (ESD) of subepithelial lesions arising from the muscularis propria include adequacy of oncologic resection and perforation risk [1-5]. We describe a case where precise endoscopic ultrasound (EUS)-guided injection into the muscularis propria allowed complete endoscopic resection of a gastric subepithelial lesion otherwise deemed inappropriate for ESD due to the extent of involvement of the muscularis propria.

A 56-year-old woman presented with a 20-mm proximal gastric subepithelial lesion. On EUS, the lesion was seen to arise from the muscularis propria within $2.4 \mathrm{~mm}$ of the diaphragm and $5 \mathrm{~mm}$ from the splenic artery ( $\bullet$ Fig. 1 ); fine-needle aspiration (FNA) was nondiagnostic. The patient opted for endoscopic resection, which was carried out under general anesthesia. The lesion periphery was marked with argon plasma coagulation dots. Subsequently, a linear echoendoscope (GF-UCT180, Olympus, Melville, New York, USA) with a 22-gauge FNA needle (Cook Medical, Inc., Bloomington, Indiana, USA) was used to inject the muscularis propria beneath the lesion with a mixture (14 mL) containing $0.83 \%$ hydroxypropylmethylcellulose, 1:10000 epinephrine, and indigo carmine to expand the layers of the muscularis propria ( Video 1 ). Thereafter, ESD was carried out [6], extending the dissection through the muscularis propria until visualization of the serosal fat through a thin transparent film ( Fig. 2). The defect was closed with three endoscopic sutures (Overstitch, Apollo Endosurgery, Inc., Austin, Texas, USA) ( Fig.3). The patient's clinical course was uneventful. Final pathologic examination confirmed a completely resected leiomyoma. jection into the muscularis propria to pro-
Our report describes an EUS-assisted in-
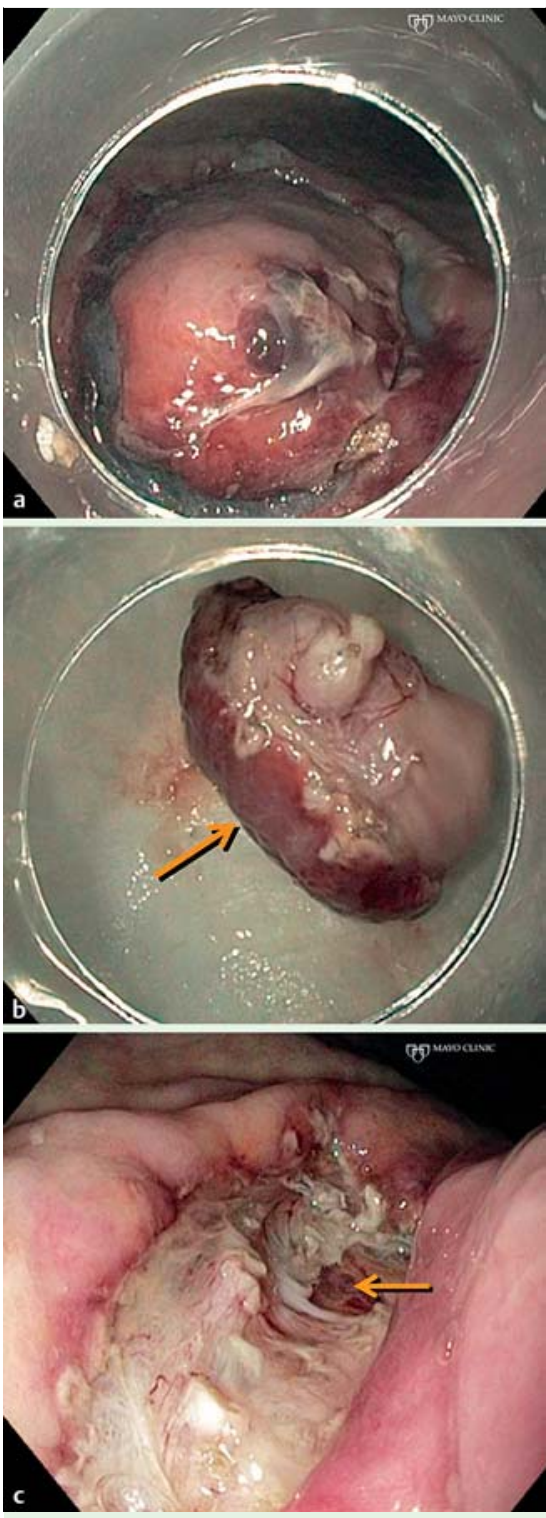

Fig. 2 a Circumferential mucosal incision. b Resection of encapsulated subepithelial lesion showing the mucosal surface (arrow) and capsule surface. c Resection defect with visualization of serosal fat (arrow).

vide a deeper safety cushion for ESD of a subepithelial lesion with broad attachment to the muscularis propria. In addition to assessing the wall layer of origin, EUS is also useful for identifying proximate structures that may impact endoscopic resection, for precise real-time image guidance during injection, and confirming an adequate lift of complex lesions. Further research is needed to define the role of EUS-assisted ESD.

Video 1

Endoscopic ultrasound (EUS)-guided injection of the muscularis propria to provide an adequate lift of the subepithelial lesion. 


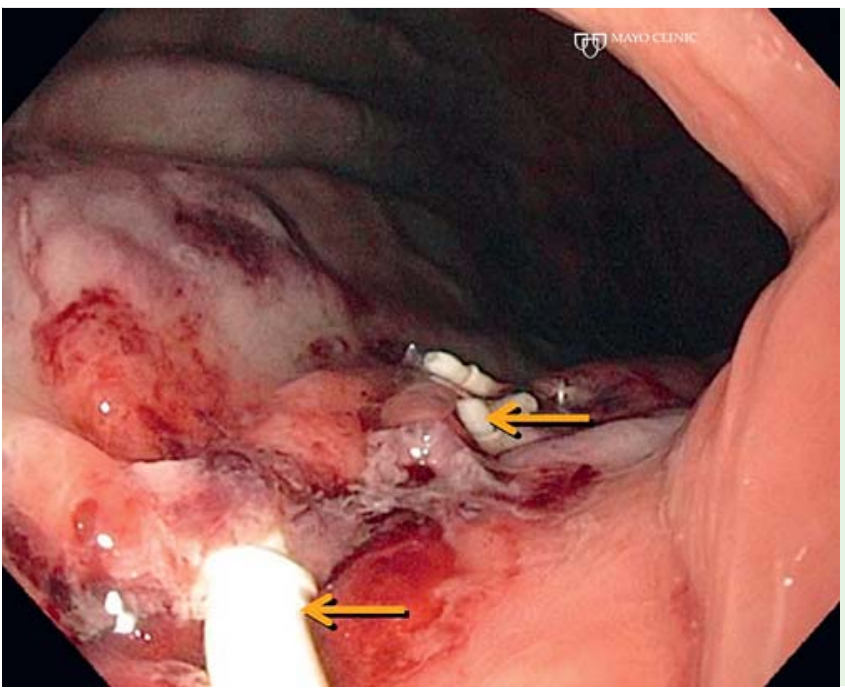

Fig. 3 Closure of the endoscopic submucosal dissection (ESD) defect with an endoscopic suturing device. The arrows indicate the stitches.

Endoscopy_UCTN_Code_TTT_1AO_2AG

Competing interests: None

\section{L. Fujii ${ }^{1}$, V. Gomez ${ }^{2}$, L. M. W. K. Song ${ }^{1}$, M. J. Levy ${ }^{1}$}

${ }^{1}$ Division of Gastroenterology and Hepatology, Mayo Clinic, Rochester, Minnesota, United States of America

${ }^{2}$ Division of Gastroenterology and Hepatology, Mayo Clinic, Jacksonville, Florida, United States of America

\section{References}

1 Bialek A, Wiechowska-Kozlowska A, Pertkiewicz $J$ et al. Endoscopic submucosal dissection for treatment of gastric subepithelial tumors (with video). Gastrointest Endosc 2012; 75: 276-286

2 Hwang JC, Kim JH, Shin SJ et al. Endoscopic resection for the treatment of gastric subepithelial tumors originated from the muscularis propria layer. Hepatogastroenterology 2009; 56: 1281 - 1286

3 Lee IL, Lin PY, Tung SY et al. Endoscopic submucosal dissection for the treatment of intraluminal gastric subepithelial tumors originating from the muscularis propria layer. Endoscopy 2006; 38: 1024-1028
4 Park YS, Park SW, Kim TI et al. Endoscopic enucleation of upper-GI submucosal tumors by using an insulated-tip electrosurgical knife. Gastrointest Endosc 2004; 59: 409415

5 Zhou PH, Yao LQ Qin XY et al. Endoscopic full-thickness resection without laparoscopic assistance for gastric submucosal tumors originated from the muscularis propria. Surg Endosc 2011; 25: 2926-2931

6 Kantsevoy SV, Adler DG, Conway JD et al. Endoscopic mucosal resection and endoscopic submucosal dissection. Gastrointest Endosc 2008; 68: $11-18$

\section{Bibliography}

Dol http://dx.doi.org/

10.1055/s-0033-1344157

Endoscopy 2013; 45: E225-E226

(c) Georg Thieme Verlag KG

Stuttgart · New York

ISSN 0013-726X

\section{Corresponding author \\ M. J. Levy}

Mayo Clinic

Division of Gastroenterology and Hepatology 2001 st St SW

Rochester

MN 55905

USA

Fax: +507-266-3931

levy.michael@mayo.edu 